\title{
Myocardial Infarction in Graves' Disease without Coronary Artery Disease
}

\author{
Takeshi Nakano, M.D., Tokuji Konishi, M.D., \\ Yasuo Futagami, M.D., and Hideo Takezawa, M.D.
}

\section{Summary}

A 45-year-old female without coronary risk factors showed a $20 \mathrm{~kg}$ decrease in body weight, hyperhydrosis, palpitations and dyspnea on exertion for 2 months, and nocturnal dyspnea for 1 month before admission. She did not notice chest pain indicative myocardial infarction or fever suggestive myocarditis. Graves' disease was confirmed by exophthalmos and elevated titers of $\mathrm{T}_{\mathbf{3}}$ and $\mathrm{T}_{\mathbf{4}}$ thyroid hormones. Cardiac catheterization studies demonstrated no significant coronary artery disease but showed akinesis of the anteroseptal and apical walls which suggested myocardial infarction.

Thyroid hormone may directly influence myocardial oxygen supply and demand and, by some unknown mechanism, cause a critical imbalance in coronary circulation resulting in myocardial infarction.

\section{Additional Indexing Words:}

Myocardial infarction Graves' disease Normal coronary artery

CHEST pain in patients with thyrotoxicosis is not uncommon, the inci1 dence being reported to be $0.5-20 \%$ (usually $10-12 \%$ ) by Burstein et al. ${ }^{1)}$ Although patients with ischemic heart disease complicating this disorder usually have associated pre-existing coronary arterial lesions, patients with angina pectoris ${ }^{2}$ or myocardial infarction without coronary artery disease $^{3)}$ have also been reported. The pathogenic mechanisms of such conditions have yet to be elucidated, but coronary vasospasm, ${ }^{4)}$ abnormal microcirculation $^{5 /}$ and thromboembolism ${ }^{6 /}$ have been suggested as possible causative factors. Publications in English written before 1980 contain reports

From the First Department of Internal Medicine, Mie University School of Medicine, Tsu, Mie, Japar.

Address for reprint: Takeshi Nakano, M.D., First Department of Internal Medicine, Mie University School of Medicine, 2-174 Edobashi, Tsu, Mie 514, Japan.

Received for publication March 12, 1986.

Manuscript revised October 2, 1986. 
of only 28 cases of myocardial infarction complicating Graves' disease. ${ }^{1)-3), 5)-8 \text { ) }}$ In this article, a patient with thyrotoxicosis complicated by asymptomatic myocardial infarction is described and the literature reviewed.

\section{Case Report}

The patient was a 45-year-old female clerk with no relevant family

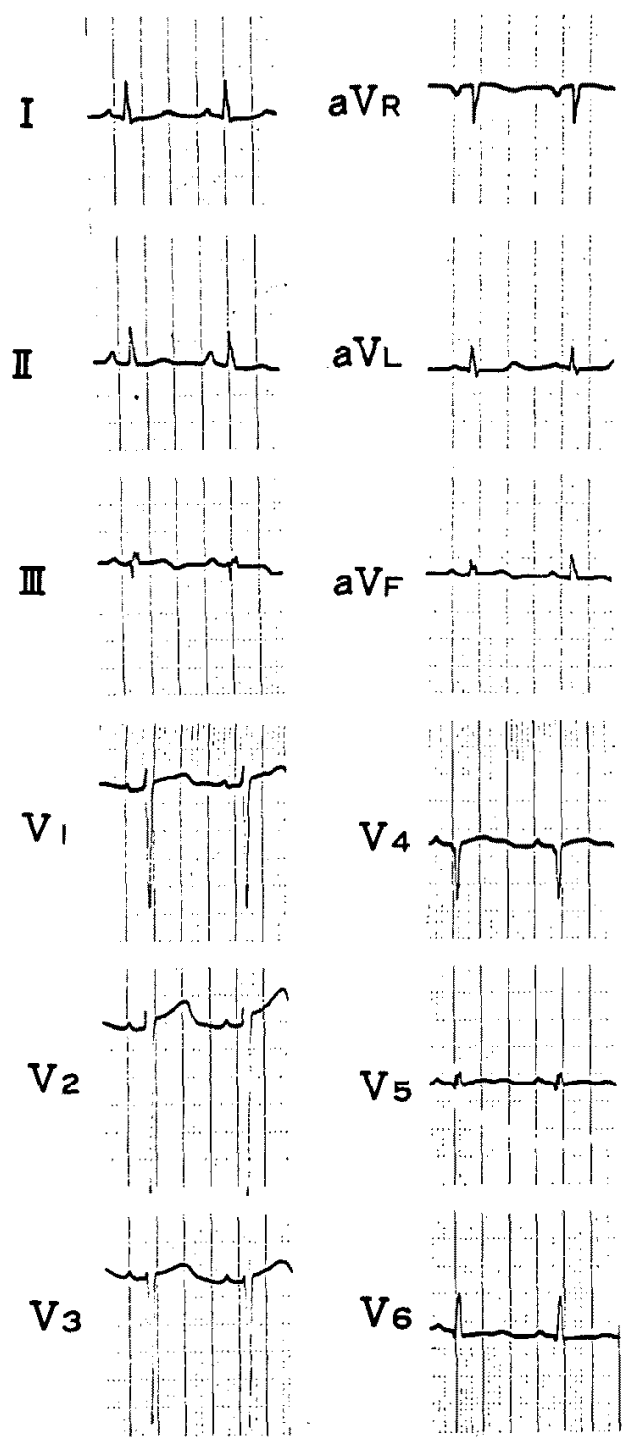

Fig. 1. Electrocardiogram taken on admission shows $Q S$ in $V_{4}$, poorly progressive $R$ in $V_{1}-V_{3}$, and flat or inverted $T$ in III and $V_{4}-V_{B}$. 
Table I. Laboratory Findings

\begin{tabular}{l|l||l|l}
\hline RBC & $531 \times 10^{4} / \mathrm{mm}^{3}$ & Fe & $35 \mathrm{r} / \mathrm{dl}$ \\
WBC & $5300 / \mathrm{mm}^{3}$ & TIBC & $417 \mathrm{r} / \mathrm{dl}$ \\
Hb & $9.1 \mathrm{~g} / \mathrm{dl}$ & T3 & $280 \mathrm{mg} / \mathrm{dl}$ \\
Ht & $32 \%$ & T4 & $12.9 \mathrm{mcg} / \mathrm{dl}$ \\
TP & $6.9 \mathrm{~g} / \mathrm{dl}$ & TSH & $1 \mathrm{U} / \mathrm{dl}$ \\
ZST & $3.3 \mathrm{U}$ & CRP & $(-)$ \\
T-Bil & $0.6 \mathrm{mg} / \mathrm{dl}$ & ESR & $8 / 20$ \\
GOT & $18 \mathrm{U}$ & PTT & $63 \mathrm{sec}$ \\
GPT & $18 \mathrm{U}$ & PT & $11.5 \mathrm{sec}$ \\
LDH & $312 \mathrm{U}$ & TEG & \\
Al-P & $3.8 \mathrm{U}$ & $\gamma$ & $9^{\prime} 30^{\prime \prime}$ \\
Ch-Ease & $0.94 \mathrm{dpH}$ & $\gamma+\mathrm{K}$ & $18^{\prime} 30^{\prime \prime}$ \\
CPK & 6 & ma & 43.0 \\
T-Chol & $151 \mathrm{mg} / \mathrm{dl}$ & fa & 33.5 \\
& & &
\end{tabular}

antiviral antibody for Coxsackie $\mathrm{B}$ group: negative

history. She had been treated 2 years before for iron deficiency anemia due to hemorrhoidal bleeding. In April, 1977, she felt general malaise, and iron deficiency anemia was noted again at a community hospital. There were no electrocardiographic abnormalities at this time. A decrease in body weight, hyperhydrosis and palpitations with no identifiable cause were noted since June, but were left untreated. In July, dyspnea during exertion and nocturnal dyspnea developed, and she lost $20 \mathrm{~kg}$ in 3 months. Since the symptoms did not improve, she was admitted to our hospital in July, 1982. No coronary risk factors were present on admission.

She was mildly thin and in no acute distress. Blood pressure was $146 / 76 \mathrm{mmHg}$, and the pulse rate was 108 per minute and regular. Although mild diffuse enlargement of the thyroid glands were noted, there was no tenderness or palpable mass. Exophthalmos was observed but ocular movement was normal. A fine tremor was present in both hands. The patient was slightly anemic, and a Levine II systolic ejection murmur was heard over the whole precordium. The chest X-ray showed cardiac enlargement with a $54 \%$ CTR, but signs of heart failure were absent. Electrocardiograms showed a QS pattern in $V_{4}$ and poor progression of $R$ waves in leads $V_{1}-V_{3}$ (Fig. 1). Biochemical blood data indicated iron deficiency anemia and primary thyrotoxicosis (Table I). Cardiac catheterization and angiography were performed 8 wecks after admission upon normalization of the thyroid function by the administration of iron preparations and merucazole ( $30 \mathrm{mg} / \mathrm{day}$ ). Cardiac catheterization revealed increased cardiac output due to anemia and thyrotoxicosis (Table II). Left ventriculogram showed akinesis in seg- 
Table II. Cardiac Catheterization and Left Ventriculography

\begin{tabular}{l|l||l|l}
\hline PAW & 11 & CO & $8.81 / \mathrm{min}$ \\
PA & $34 / 14-21$ & CI & $6.11 / \mathrm{min} / \mathrm{m}^{2}$ \\
RV & $33 / 2$ & LVEDV & $158 \mathrm{ml}$ \\
RA & 0 & LVESV & $90 \mathrm{ml}$ \\
LV & $134 / 14$ & LVEF & 0.43 \\
AO & $138 / 64 \overline{90} \mathrm{mmHg}$ & &
\end{tabular}

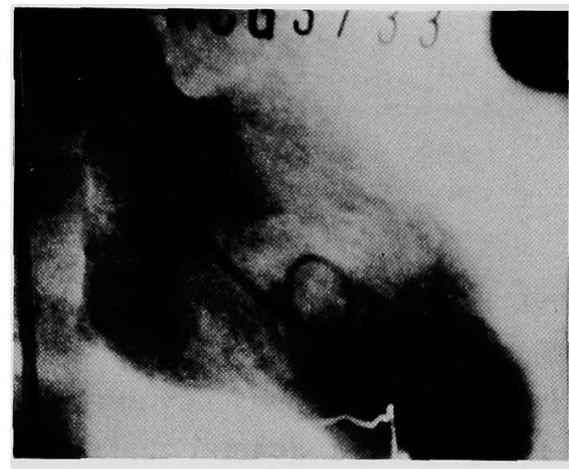

ED

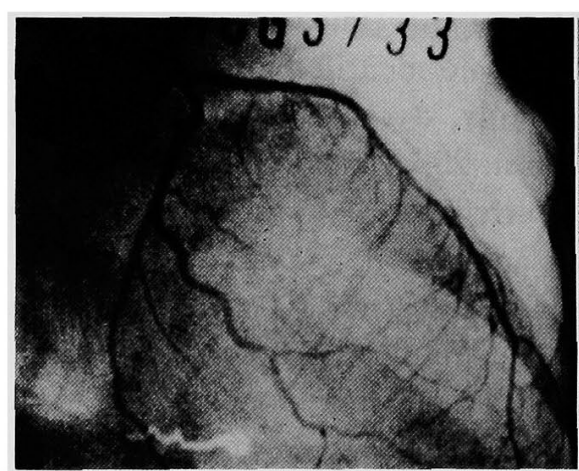

LCA

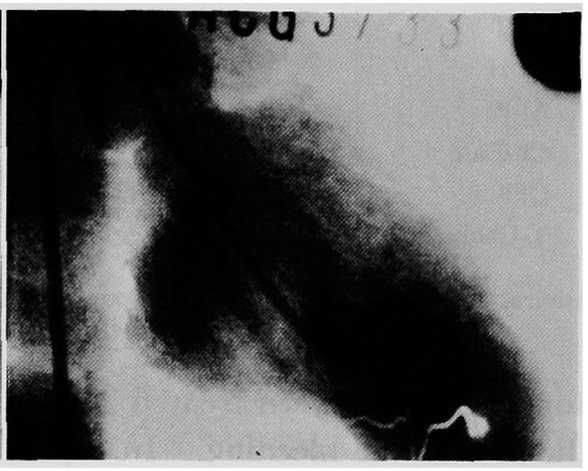

ES

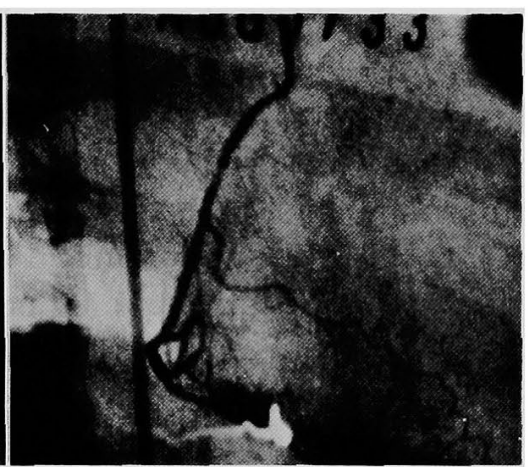

RCA

Fig. 2. Left ventriculogram in right anterior oblique projection shows akinesis of anterolateral and apical segments. $\mathrm{ED}=$ end diastole; $\mathrm{ES}=\mathrm{end}$ systole.

ments 2, 3, 4 and 6 and normokinesis in segments 1, 4, 5 and 7 (Fig. 2). Coronary angiography (Fig. 2) showed no lesions. An ergonovine loading test was not performed. The patient followed an uneventful course after discharge and was without chest pain or heart failure. 


\section{Discussion}

Hyperthyroidism may elevate the oxygen consumption of the heart by increasing each of the three principle determinants of myocardial oxygen requirement, that is, blood pressure, heart rate and contractile state. However, the disease may also be associated with such complications as heart failure, ${ }^{91}$ atrioventricular block, ${ }^{10)}$ angina pectoris ${ }^{2)}$ and myocardial infarction. ${ }^{3)}$ Concurrence of thyrotoxicosis and myocardial infarction has been reported in 28 patients in Europe and America, but most of these patients had pre-existing coronary disorders. Only 7 patients, ${ }^{3,5)-8)}$ including ours, showed normal coronary arteries.

The possible causes of the abnormal left ventricle in this patient include myocardial infarction without coronary disease, myocarditis and thyrotoxic cardiomyopathy. Although the symptoms of acute viral myocarditis can vary widely among individuals, $60-80 \%$ of patients usually have fever. In about one-fourth of the patients, fever will be high and may persist for 2-3 weeks after the acute illness. Furthermore, chest pain, which is the second most common symptom, may be present in $67-72 \%$ of patients. In this case, there was no fever or chest pain in spite of a reexamination of the clinical history in detail. Although the possibility of viral myocarditis could not be excluded on the bases of the clinical course and viral antibody titer, we prefer coronary artery disease as the probable etiology in this patient. Although experimental viral myocarditis may even produce ventricular aneurysms, ${ }^{11)}$ a left ventriculogram showed abnormalities only in the area supplied by the left anterior descending coronary artery, suggesting myocardial necrosis caused by global ischemia. As possible causes of myocardial infarction in patients with normal coronaries, coronary spasm, ${ }^{31}$ thromboembolism with recanalization of the lumen, ${ }^{6 /}$ abnormal platelet function ${ }^{12)}$ or abnormal microcirculation have been suggested. In this patient, however, there was no evidence of chest pain or abnormalities in the blood coagulation tests, and arrhythmias such as atrial fibrillation or embolism in other organs were absent.

Coronary spasm is considered today to be a possible cause of myocardial ischemia in thyrotoxicosis, and has been demonstrated in 2 patients with angina pectoris. ${ }^{4), 13)}$ Yasue et al $^{14\}}$ suggested that imbalance of autonomic nerve activity may accelerate the coronary artery spasm. However, several experimental studics ${ }^{15), 16)}$ showed that it is difficult for thyrotoxicosis alone to produce coronary artery spasm. Although the mechanisms of myocardial ischemia in patients with hyperthyroidism remain unclear, the presence of ischemic heart disease is not uncommon and we must be alert for this in the treatment of thyrotoxicosis. 


\section{REFERENCES}

1. Burstein J, Lamberg BA, Eramaa E: Myocardial infarction in thyrotoxicosis. Acta Med Scand 166: 379, 1960

2. Somerville W, Levine SA: Angina and thyrotoxicosis. Br Heart J 12: 245, 1950

3. Kotler MN, Michaelides M, Bouchard RJ, Warbasse JR: Myocardial infarction associated with thyrotoxicosis. Arch Intern Med 132: 723, 1973

4. Wei JY, Genecin A, Greene HL, Achuff SC: Coronary spasm with ventricular fibrillation during thyrotoxicosis: response to attaining euthyroid state. Am J Cardiol 43: 335, 1979

5. Hoshino $\mathrm{T}$, Aya $\mathrm{S}$, Yamazaki $\mathrm{H}$, Ayabe $\mathrm{T}$, Nakamura $\mathrm{Y}$ : Akuterer Myokardinfarkt bei einem jungeren Patienten mit Hypertyreose. Z Kardiol 67: 99, 1978

6. Gordon JA, Lenkei SC: Thyrotoxicosis associated with myocardial infarction. Can Med Assoc J 90: 1128, 1964

7. Proskey AJ, Saksena F, Towne WD: Myocardial infarction associated with thyrotoxicosis. Chest 72: 109, 1977

8. Symmes JC, Lenkei SG, Berman ND: Myocardial infarction, hyperthyroidism and normal coronary arteries: report of two cases. Can Med Assoc J 117: 389, 1977

9. Sandler G, Wilson GM: The nature and prognosis of heart disease in thyrotoxicosis. QJ Med 28: 347, 1958

10. Muggia AL, Stjernholm M, Houle T: Complete heart block with thyrotoxic myocarditis. New Engl J Med 283: 1099, 1970

11. Zate M, Itskan SB, Sanger $R$ et al: New linkage data for the X-linked types of muscular dystrophy and G6PD variants, color blindness, and $\mathrm{Xg}$ blood groups. J Med Genet 11: 321 , 1974

12. Steele P, Rainwater J, Vogel R: Abnormal platelet survival time in men with myocardial infarction and normal coronary arteriogram. Am J Cardiol 41: 60, 1978

13. Featherstone HJ, Stewart DK: Angina in thyrotoxicosis: thyroid related coronary artery spasm. Arch Intern Med 143: 554, 1983

14. Yasue H, Touyama M, Shimamoto M, Kato H, Tanaka S, Akiyama F: Role of autonomic nervous system in the pathogenesis of Prinzmetal's variant form of angina. Circulation 50: 534,1974

15. Williams RS, Lefkowitz RJ: Thyroid hormone regulation of alpha-adrenergic receptors: studies in rat myocardium. J Cardiovasc Pharmacol 1: 181, 1979

16. White CW, Zimmerman TJ: Reduced cholinergic sinus node restraint in hyperthyroidism. Circulation 54: 890, 1976 